\title{
CAROLINA VON KOSERITZ
}

\section{Hilda Agnes Hübner Flores*}

O tempo se encarregou de retirar das estantes de livros a obra de Carolina von Koseritz e de apagar da memória o importante papel que exerceu, a seu tempo, na esfera sócio-cultural. Ao ensejo do centenário da publicação de sua primeira tradução, e do $40^{\circ}$ aniversário da Academia Literária Feminina do Rio Grande do Sul, da qual é uma das patronas, cabe um retraçado, incompleto embora, de seu perfil de mulher atuante.

Ao lado de poetisas como Camila Furtado Alves, Rivocata Heloisa de Melo e Ana Aurora do Amaral Lisboa, ou da abolicionista Luciana de Abreu, foi das raras mulheres que, no século passado, transpuseram os umbrais domésticos para se impor por sua capacidade intelectual. Contista e tradutora, reside seu maior mérito no fato de haver oferecido ao leitor brasileiro uma nova opção de temática, quando entre nós imperava um exclusivista francesismo cultural.

Se o Tratado Comercial de 810 assegurou à Inglaterra a dominação econômica, coube à França o predomínio cultural desde a chegada, em 1817, da Missão que implantou no Rio de Janeiro nossa primeira Escola de Belas Artes, legando-nos um gosto acentuado por tudo que se referia à pátria de Voltaire. Basta lembrar Jean Baptiste Debret e Arsènne Isabelle como documentaristas-mor, retratando nossa sociedade por várias décadas. O primeiro, bonapartista, desenhou a bandeira do recém formado Império nos moldes da napoleônica: losango incrustrado em um retângulo, substituindo apenas as cores daquela pelo verde e amarelo das Casas de Bragança e dos Habsburgos.

O positivismo comtiano, a partir da década de 1870 , encontrou fervorosos seguidores entre intelectuais e militares, exaltando a precisão científica e ditando o gosto pela simetria e equilibrio de linhas da arquitetura neo-clássica, nascendo monumentos como a Biblioteca Pública de Porto Alegre e o

- Professora de Estudos Brasileiros na FAliECOS, PUC, e ocupante da cadeira no 15 da Academia Literária Feminina do RS. 
templo positivista, inacabado, à av. João Pessoa. Doutrinariamente, propalou a superioridade do regime republicano, sendo responsável pela queda do Império e marcando profundamente os atos iniciais da República. Nos centros urbanos proliferavam os "restaurantes", importávamos perfumes de Paris, seda francesa e os jornais anunciavam chita "à Pompadour".

Foi nesse clima que viveu Carolina von Koseritz. Nascida em Porto Alegre, a 23 de outubro de 1865, teve a dita de ser filha do grande crítico, editor, teatrólogo, romancista, político, homem de imprensa e cultor do germanismo, Carlos Julio Cristiano Adalberto Henrique Fernando von Koseritz e de Zeferina Maria Barbosa, filha da vastidão dos pampas de Cangussu, RS.

Teve três irmãs: Adelaide, Zelinda e Zeferina, todas de prendas domésticas. Sua infância decorreu em meio aos des. velos maternos e ao exemplo de produtividade intelectual e capacidade de luta que caracterizaram seu pai. Dele auferiu o gosto pelas letras, o que the valeu ser sua "menina dos olhos", secretariando-o ao mesmo tempo que aprendia. Muito cedo estreiou no mundo das letras: aos 12 anos, segundo bibliógrafos; mas, sua filha Áurea Estela Feijó, simpática septuagenária, atualmente residente em Novo Hamburgo, e que conviveu com amãe até os 15 anos de idade, garante que, aos 16 ou 17 anos, Carolina teria publicado seu primeiro conto em um periódico de Porto Alegre. Sendo-lhe muito importante a opinião paterna, submeteu-o à apreciação de Koseritz, omitindo autoria, explicando apenas tratar-se de pessoa jovem. Koseritz, após leitura cautelosa, teria opinado que, sendo jovem, a autora devia ser muito inteligente. Carolina identiifcou-se e os dois selaram num longo abraço a afinidade intelectual que os unia.

Entre abril e julho de 1883 o então deputado provincial Carlos von Koseritz viajou com sua familia para o Rio de Janeiro, e Carolina entrou em contato com o mundo intelectual carioca, onde chegavam ecos do movimento contestatório, germanista, da Escola de Direito de Pernambuco. O mulato Tobias Barreto, de palavra fluente e persuasiva, pregava convicto a superioridade da cultura germân ca: a Alemanha ensinava a pensar e a França, a escrever, afirmava. Clovis Bevilacqua, Silvio Romero, os historiadores Capristrano de Abreu e Oliveira Lima e outros intelectuais de escol igualmente abraçaram estas idéias, reagindo contra o modismo da época, de que tudo o que era bom vinha da França. Dezenas de estudantes de Direito paulistas transferiam-se para Recife, retornando embebidos de idéias germanófilas que difundiam pelos centros urbanos. 
Ainda que não intencionalmente, Carolina engajou-se nesse movimento com suas traduçöes para a lingua nacional. $\mathrm{Na}$ capital do Império, estreitou ela amizade com o poeta e escritor Ferdinand Schmid, cônsul da Áustria e dos países helvéticos, sua pátria. Em 1868, com o pseudônimo de Dranmour, editara ele o poema REQUIEM. Carolina o traduziu ao português, publicando-o no Rio de Janeiro, em 1883. Ao prefaciá-lo, Sílvio Romero, crítico renomado, professor do Colégio D. Pedro II, autor de "Contos Populares Brasileiros" e de "Estudos da Literatura Contemporânea" ( 3 vol.), ressaltou o mérito da tradutora "quase menina", responsável por um novo intercâmbio cultural, opondo-se ao monopólio francês.

Em Porto Alegre, a imprensa enalteceu o sucesso da contista, agora também tradutora. Dranmour exultou, afirmando que o trabalho de Carolina vinha ao encontro da filosofia de "Allgemeiner Deutsche Zeitung", jornal carioca de sua direção: "intensificar as relações culturais e materiais entre o Brasil e os países de fala alemã". Ele próprio dava exemplo disso, vertendo para a língua de Goethe nossos poetas Álvaro de Azevedo (Sonhando) e Gonçalves Dias (Teus olhos).

Carolina correspondeu à expectativa dos críticos, quando em 1884 veio a lume, em primorosa edição de 76 páginas, da Gundlach de Porto Alegre, a tradução de HERRMANN E DOROTEA, poema lírico-idílico mundialmente consagrado do imortal alemão Johann Wolfgang Goethe. O público aplaudiu. A imprensa festejou. Dranmour ressaltou as qualidades do poema em si, da tradução primorosa e da tradutora, "promessa de futuro da juventude brasileira".

O apogeu literário de Carolina serviu de pretexto para atiçar diferenças políticas: Hans von Frankenberg, deputado provincial como Koseritz, atribuiu a este a autoria da tradução goetheana, escrevendo em seu jornal "Deutsche Zeitung" (21.4.1884) não ter Carolina capacidade para tal trabalho, realizado pelo pai, por vaidade pessoal. Não sei se Koseritz, habitualmente combativo, alimentou a polêmica, mas seus amigos e os trabalhos posteriores de Carolina, mesmo após a morte do pai, mostraram o contrasenso do injuriador que, diga-se de passagem, teve rejeitada pelo Conselho Diretor da Escola Normal (atual Instituto de Educação Gen. Flores da Cunha), onde lecionava História, sua volumosa obra "História do Brasil", por inadequada, mera compilação de fatos; em 1886 às pessas teve de buscar exílio em Buenos Aires, suspenso que foi por Mal. Deodoro do exercício de suas funções, por haver publicado 
uma paródia de nosso hino nacional, considerada ultrajante pelas autoridades.

Franklin Távora, proeminente literato cearense, analisou a obra de Goethe e sua tradução, posteriormente publicado em edição tetra-língüe (espanhol, francês, inglês e alemão). Chama ele atenção para o fato de Carolina haver abordado temas diametralmente opostos em seus dois primeiros trabalhos de estréia: HERMANN E DOROTEA exalta a vida, o amor do primeiro enlace, o idilico épico de dois jovens que se dão as mãos para entrar no mundo idealizado da família, ao passo que REQUIEM é um solene e majestoso adeus, uma despedida à humanidade e ao mundo. Reconhece imperfeições gramaticais, apesar do que o trabalho de Carolina é de uma "harmonia singela e comotora, brandura maviosa, linguagem de ternura inocente", partindo, o que é raríssimo, de uma "mulher jovem e inteligente, cujo espírito se agita nas letras, em demanda da glória e do renome" (Jornal do Comércio, Porto Alegre, 20 e 27.7.1884).

Se Carolina buscou renome, fê-lo pela laboriosidade, dentro de seu lema de vida evocado pela filha, a quem entrevistei pessoalmente: "ser boa, bonita e culta".

Argymiro Galvão, gaúcho estudando Direito em São Paulo, expressou sua admiração pela paciência e tenacidade, virtudes tipicamente femininas que permitiram à Carolina abrir novos horizontes ao leitor, um novo mundo cultural. Prevê para a jovem o mesmo lugar na literatura brasileira, que Alice Durant ocupava na França. (Jornal do Comércio, P. Alegre, 27.7.1884).

Enquanto a crítica promovia a ascenção da jovem talentosa e bela, esta, representante oficial da Sociedade Germânia, desvendou sua versatilidade pessoal, engajando-se de corpo e alma no movimento abolicionista que libertou os escravos em Porto Alegre, em 1884. O Centro Abolicionista, organizado pelo Partenon Literário, Sociedade Cultural cujas fileiras seu pai integrava, congregou todas as forças vivas da capital. Campanhas, teatros, recitais, festas filantrópicas, sobressaindo-se a grande kermesse do dia 7 de setembro. Constituiram Comissöes, Carolina à frente de uma delas.

Ao lado de Sofia Veloso, Afonsina Reis, Leopoldina Chaves, Elisa Camargo, Amália Haensel, Maria Jesuina Gay e outras damas da elite social, angariava brindes e publicava na imprensa sucessivas nominatas dos doares e dos mimos ofertados - aliás, um belo material para estudo sociológico da 
época. Em sua tenda "Rio Grande do Sul", armada em frente à igreja matriz, na Praça D. Pedro II, hoje Mal. Deodoro, transformou as ofertas em fundos pró compra de alforria, ela que vira seu pai libertar os escravos trazidos ao casamento pela esposa.

Se Carolina agradeceu de público as colaborações recebidas, por outro lado a imprensa informava sobre sua eficiente atuação:

"No meio de sua pitoresca tenda distinguiase Carolina von Koseritz, duplamente aureolada - pela caridade e pelo talento. Ao seu apelo corria-se com intima alegria e sua amabilidade era correspondida atenciosa e agradavelmente..." (Jornal do Comércio, P. Alegre, ....... 10.9.1884).

Aos 20 anos de idade, informa a imprensa, Carolina representou a Sociedade Germânia, perante as demais Sociedades alemãs ou teuto-brasileiras, nos festejos carnavalescos. A 17 de maio do mesmo ano, 1885, foi acometida de "grave enfermidade", mas já em dezembro, enquanto com sua irmã Adelaide participava do Bazar Natalino pró Beneficência Portuguesa, o Jornal do Comércio comunicou sua tradução do poema EXCELSIOR, de Langfellow, a partir da versão para o francês, de seu amigo Dranmour. Um verdadeiro círculo de intercâmbio cultural!

Em 1886 Carolina produziu generosamente, talvez para compensar a ausência do pai que por meio ano viajara à Europa, visitando mãe e familiares que não vira desde que imigrara, há 36 anos. A VINGANÇA DAS FLORES (fevereiro) e UMA FLOR FENECIDA (outubro) condenam o descaso com a natureza, evidenciando um despertar precoce de consciência ecológica. Nos meses de maio e junho o Jornal do Comércio local publicou em seriado O GRILO DA LAREIRA, tradução do conto de Charles Dickens cujos personagens de coloração viva, extraídos do dia-a-dia humano, são envolvidos em uma trama crescente.

Seguem vários contos de costumes, nos quais Carolina analisa com grande discernimento a problemática social da época. Para fugir à sanção social, usa o pseudônimo de Walquíria Cerstonez: UMA DOR DE CABEÇA narra as aventuras de um D. Juan mal sucedido em uma noite de baile; $A$ 
FREIRA explora o tema do amor-paixão frustrado, bem ao gosto do romantismo oitocentista, acabando a principal protagonista refugiando-se no claustro; O PERFIL analisa o drama da mocinha criada em meio a mimos e devaneios, mal preparada para a vida, para quem o debut se transforma em desilusão por não encontrar o "príncipe" idealizado; O LEITO ESPANHOL é conto prenhe de romantismo.

RELIQUIAS VIVAS é romance de Turguenoff. Traduzido por Carolina, foi editado em Portugal em 1884, mas parece que só chegou ao conhecimento do leitor brasileiro em 1887. Do mesmo autor, Dr. Argymiro Galvão traduziu "Poemas em Prosa". Turguenoff explora, com tonalidade psicológica, cenas da vida real. Em Relíquias Vivas exalta a nobreza de sentimentos humanitários, principalmente quando sublimados pelo sofrimento.

Do inglês Lord Byron, Carolina traduz três obras: MANFREDO, que opõe à dinâmica de ação a manipulação psicológica dos personagens; MAZERA e OSCAR D'ALVA, que refletem diversas facetas do mundo europeu e oriental, por onde andara viajando o autor, expulso da pátria.

$\mathrm{O}$ ano de 1890 reserva grave golpe para Carolina: a morte de Koseritz, seu pai, seu mestre, seu confidente de todas as horas. Época de acirradas agitações políticas, Koseritz faleceu a 30 de maio, vitimado por síncope cardiaca, após confinamento domiciliar, imposto pelos legalistas, que seguirem combatendoo post-mortem. Carolina reagiu ao ataque inimigo. A política não era seu chão, mas não era admissivel ver o nome do pai ultrajado. Com excepcional valentia posicionou-se face aos redatores de "A Federação", entre eles a figura proeminente de Dr. Assis Brasil, para corrigir distorções de fatos e ocorrências que a paixc̃o política facilmente logra gerir. Seu repto saiu publicado nos jornais da capital, nacionais e de língua alemã. Os opositores silenciaram.

Em 1892, aos 27 anos de idade, contraiu núpcias com o cearense Rodolfo Brasil, filho do negociante português João Maria de Oliveira Cardoso e da índia Maria Antonia Baptista de Moraes Cardoso. Por que a diferença de sobrenome de pai para filho? Narrou-me Aurea Estela que Rodolfo acreditara que sua mãe, cataléptica, houvera sido enterrada viva, fato do qual culpou o pai, abandonando por isso a casa paterna ainda criança, e trocando de sobrenome mais tarde. Foi educado em seminário, mas não quis ser padre. Seguiu a carreira militar, 
chegando ao posto de coronel. Exerceu a profissão de engenheiro militar. Adepto de Büchner, Spencer, Darwin e Haeckel, simpatizava com o naturalismo então em voga - com o que encontrou afinidade com seu futuro sogro, Carlos von Koseritz.

Rodolfo conheceu Carolina através de seus trabalhos publicados. Apaixonou-se. No Ano Novo de 1886, sob o pseudônimo de Rodolfo Paixão, dedicou-lhe, no Jornal do Comércio de Porto Alegre, idílica poesia, "A Mulher", no mesmo ano inserida em seu livro "Mistilineas", cujo valor literário Damaceno Vieira e Apeles Porto Alegre colocaram em dúvida, através do mesmo jornal (18.4 e 9.5.1866). O namoro foi por correspondência. Rodolfo veio para noivar. O encontro pessoal foi de certa decepção para Carolina: ela era alta, loira, de olhos azuis, elegante, idealista, e Rodolfo, baixo, gordo, meio careca, bugre... Por que casaram? Talvez para atender desejo da mãe de Carolina, viúva, sra. de poucas letras como era usual na época, que desta maneira pensava ver amparada a filha.

O casamento ocorreu a 6 de agosto, na igreja Luterana de Porto Alegre, para a qual Koseritz aderiu anos antes, após sustentar séria polêmica com a igreja católica, particularmente com a ordem jesuítica. O primogênito do casal, Carlos, nasceu em 4.10.1893, na cidade portuária de Rio Grande, para onde Rodolfo fora transferido. O segundo filho, João, nasceu no Rio de Janeiro, onde a família residiu por vários anos, Carolina colaborando para jornais, inclusive para a página social, dando conselhos de beleza e de utilidades domésticas. Usava os pseudônimos de Augusta Dolores e Aurea Estela, este último posteriormente dado à filha. Rodolfo descuidou da família. Perscrutava o céu à procura de algum astro ainda não identificado, para lhe legar o nome. Não achou. Parece que na Biblioteca Nacional há trabalhos de ambos.

Fracassado o casamento, Carolina, magoada, retornou a Porto Alegre. Aqui tentou refazer a vida, desta vez com o jornalista Mário Teixeira de Sá. Nascido no Rio de Janeiro em 25.3.1871, Mário era militar, tendo participado de Revolução de 1893, reformando-se como tenente em 1903. Atuou como jornalista a maior parte de sua longa vida, pois faleceu em Porto Alegre aos 88 anos, em 7.6.1959.

Atuou no interior - Uruguaiana e Novo Hamburgo - e na capital, além de ter sido tradutor, com obras publicadas pela Globo. Foi redator do Correio do Povo nas décadas de 1920 e 1930: letra homogênea, vocabulário vasto, estilo Camilo Castelo 
Branco cuja obra apreciava, polemista tremendo, linguagem ácida, agressivo, irônico, oposicionista ferrenho da Federação - assim o descreve o veterano jornalista Breno Caldas, que o conheceu por longos anos. Tão violentas eram suas crônicas que, às vezes, dava-se mal, como aconteceu em Uruguaiana, onde trabalhavam para "A Nação", jornal de propriedade de Manoel Pacheco Prates. Hostilizando a familia Fagundes, de projeção local, escreveu "A Fagundagem", violento editorial de ataque. Largou-o na redação e embarcou incontinenti no trem noturno, rumo a Porto Alegre, antes que o delegado andasse em seu encalço.

Se era agressivo na vida profissional, não muito diverso aconteciam as coisas na vida da familia, constituída, aliás, sobre bases socialmente intoleradas na época, em virtude do casamento anterior de Carolina. Os dois filhos do primeiro matrimônio, intolerados pelo padrasto, foram criados por uma tia. O casal teve 4 filhos: Aurea Estela, a úniva viva e informante, Isis, Celso e Estério. Houve acertos e desacertos. Carolina chegou a viajar para o Rio de Janeiro, mas Mário foi em busca de reconciliação. Permaneceram unidos enquanto os fithos eram pequenos.

Aurea Estela recorda com carinho sua infância passada junto à mãe que era amorosa, solícita, boa dona de casa. Gostava de fazer doces, tendo publicado um livro de receitas. Havia pinheirinho no natal e na páscoa, ovos escondidos pelo páteo da casa na rua da Varzinha e depois na Luis de Camões, no bairro Partenon de Porto Alegre. Para o debut da filha, deu-lhe um anel em forma de coração, verde - cor da esperança com 15 brilhantes.

Carolina produziu bastante. Preferia escrever à noite, até de madrugada. Muitos de seus escritos permaneceram inéditos. Contactei-lhe três contos datados de 1919: EPISÓDIO OBSCU$\mathrm{RO}$, editado no número especial para $\circ 5^{\circ}$ aniversário da Revista "Kodak", em 2.8.1919, e que se refere a um ato de heroísmo ocorrido durante a Guerra dos Farrapos, na qual lutou um ancestral seu; RISOS E SORRISOS e ANTIGUALHAS foram publicados na Revista "Norte-Sul", edição da Globo. No primeiro Carolina analisa a variada gama de sentimentos humanos escondidos atrás de um sorriso; Antigualhas encerra reminiscências do sofrimento que a vida lhe reservou. Há informação de que tenha traduzido "Os Últimos Moicanos", cuja adaptação para televisão teria sido levado ao ar na década de 1960. 
A grande afinidade espiritual que teve com seu pai, Carolina conservou-a por toda a vida. Cultuou seu retrato e visitava seu túmulo. Estela acompanhava-a, aos domingos à tarde. Criança ainda, ficava brincando em volta, enquanto a mãe se demorava em saudoso solilóquio, buscando orientação e alento para o amanhã.

Carolina contraiu uremia, enfermidade que the restringiu gradativamente as capacidades vitais. Mas seguiu escrevendo enquanto pôde. Profundamente amargurada, pediu à filha que fizesse acompanhar seus restos mortais com seus escritos não publicados, já que a ninguém mais interessavam. Perdeu-se assim, para sempre, apreciável parcela da produção de Carolina. Tão profunda era a mágoa pelas experiências frustradas, que aconselhou à filha que evitasse o casamento, por não ser um estado de vida que trazia felicidade. Estela, entretanto, confessa que fez bem em "desobedecer", pois foi muito feliz em sua vida matrimonial.

Assistida pelo Dr. Annes Dias, Carolina faleceu aos 56 anos de idade, a 22.1.1922, recebendo sepultura junto ao pai, no jazigo perpétuo n: 3054 do cemitério Luterano de Porto Alegre, doação da Comunidade Luterana, em reconhecimento ao grande vulto histórico que foi Carlos von Koseritz.

Em 1943, quando Lydia Moschetti idealizou criar um oasis cultural em meio às dezenas de obras sociais e assistenciais que fundou ao longo de sua vida, escolheu, numa homenagem póstuma mais que merecida, Carolina von Koseritz como patrona da cadeira no 15 da Academia Literária Feminina do Rio Grande do Sul (ALFRS), Academia que ora completa 40 anos de ininterruptos trabalhos e se orgulha de ser a mais antiga do pais exclusivamente feminina, num pioneirismo semelhante ao desta patrona, isto é, projetando a capacidade feminina além dos umbrais domésticos, em busca do lugar adequado que cabe à mulher na sociedade atual.

O vereador Viton de Araújo em 1982, pouco antes de falecer, por lei municipal, deu a uma rua de Porto Alegre o nome desta mulher invulgar. 


\section{BIBLIOGRAFIA}

BLACKE, Sacramento: Dieionário Brasileiro Bibliográfieo, Rio de Janeiro, Imprensa Oficial/1893, Vol. II.

Entrevistas com familiares e profissionais.

GENEALOGISCH - HISTORISCHE BESCHREIBUNG, nebst denen Stamm und Ahnen-Tafeln des Uhralten Edelichen Geschlechtes derer D. von KOSERITZ, s/autor, s/d. (propriedade da familia).

GOETHE, J. W.: Herrmann o Dorotea, trad. de Carolina von Koseritz, Porto Alegre, Gundlach/1884.

Jornais da década de 1880 e início de 1890: A Federação, A Reforma, Jornal do Comércio, Deutsche Zeitung, Koseritz Deutsche Zeitung.

Livros TOMBO da Comunidade Luterana de Porto Alegre.

MARTINS, Ary. Escritores do RGS, Porto Alegre, IEL/1978.

Revista KODAK, Porto Alegre, 1919.

Revista NORTE-SUL, Porto Alegre, 1919.

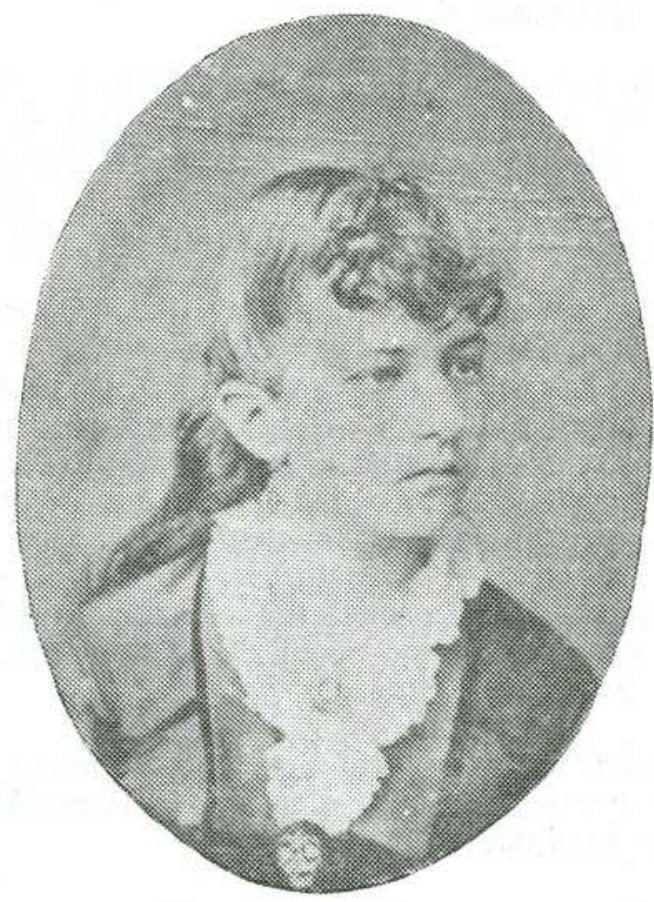

Carolina Von Koseritz 